\title{
Collaboration Strategy Based on Conflict Resolution for Flatness Actuator Group
}

\author{
Zhu-Wen Yan $\mathbb{D}^{1},{ }^{1}$ Bao-Sheng Wang $\mathbb{D}^{1},{ }^{1}$ He-Nan Bu $\mathbb{D}^{2},{ }^{2}$ Long Pan $\mathbb{D}^{1},{ }^{1}$ Lei Hong $\left(\mathbb{D},{ }^{1}\right.$ \\ Dian-Hua Zhang $\mathbb{D}^{\mathbb{D}}{ }^{3}$ Hong-Yu Wang $\mathbb{D}^{4},{ }^{4}$ and Dong-Sheng $\mathrm{Lv} \mathbb{D}^{1}$ \\ ${ }^{1}$ Jiangsu Provincial Engineering Laboratory of Intelligent Manufacturing Equipment, \\ Industrial Technology Research Institute of Intelligent Equipment, Nanjing Institute of Technology, Nanjing 211167, China \\ ${ }^{2}$ School of Mechanical Engineering, Jiangsu University of Science and Technology, Zhenjiang 212003, China \\ ${ }^{3}$ State Key Laboratory of Rolling and Automation, Northeastern University, 3-11 Wenhua Road, Shenyang, China \\ ${ }^{4}$ Transportation Engineering College, Dalian Maritime University, No. 1 Linghai Road, Dalian, China \\ Correspondence should be addressed to He-Nan Bu; hnbu520@just.edu.cn
}

Received 21 November 2019; Accepted 2 April 2021; Published 17 April 2021

Academic Editor: Leandro F. Miguel

Copyright (c) 2021 Zhu-Wen Yan et al. This is an open access article distributed under the Creative Commons Attribution License, which permits unrestricted use, distribution, and reproduction in any medium, provided the original work is properly cited.

\begin{abstract}
During the flatness control process, there are frequently some uncoordinated regulating behaviors in the flatness actuator group. This has a bad influence on the flatness control accuracy and the flatness control efficiency. Therefore, a collaboration strategy based on conflict resolution for the flatness actuator group has been proposed in this paper. First of all, the feature of flatness measurement value is extracted through establishing the actual flatness condition discriminating factor. After that, the coordination cooperation that is appropriate to the actual flatness condition is developed for the flatness actuator group. Finally, the optimal adjustment of the actuator population is solved by the coordinated algorithm of Topkis-Veinott and genetic algorithm collaborative optimization. The collaboration strategy proposed in this paper has been successfully applied to a flatness control system of a $1450 \mathrm{~mm}$ five-stand cold rolling mill.
\end{abstract}

\section{Introduction}

With the steel industry promotion and development, the strip flatness quality receives more and more attention [1]. Some researchers have tried to improve the flatness control effect by establishing a high-precision flatness closed-loop control algorithm. Zhang et al. adopted GA to optimize PIDNN and proposed flatness intelligent control method based on GA-PIDNN for $900 \mathrm{HC}$ reversible cold rolling mill in this paper [2]. Wang et al. proposed a new multivariable optimization algorithm with global convergence for a cold rolling mill flatness control [3]. Prinza et al. developed a new feedforward control approach for the thickness profile of the strip in a tandem hot rolling mill [4]. However, they relied too much on the computing power of the controller. In addition, some researchers have analyzed the effect of a single type of actuator on the strip flatness. Wang et al. presented an investigation on the shape prediction and control of strip [5]. Voronin et al. showed the distribution of the roll gap along the length of the roll body according to the horizontal displacement of the work rolls [6]. However, they did not consider the uncoordinated regulating behaviors between the flatness actuator group.

In the actual application process, the main incongruous actuator group behaviors are as follows: When a symmetrical flatness defect is detected by shapemeter roll, the work roll tilting may participate in the flatness regulating process [7-9]. However, the additional flatness change is caused by work roll tilting, which will consume the regulating margin of other actuators in the flatness closed-loop control system [10-12]. When the direction of work roll bending is opposite to the direction of intermediate roll bending, since the regulating efficiency curves of these two actuators are both concave, the offset between the effects of the two actuators on the strip flatness cannot be avoided [13-15]. When the intermediate roll shifting is alternately decreased and 
increased, the massive thermal deformation is generated in this contact area between work roll and intermediate roll, which can lead to serious roll wear [16-18].

In the existing flatness control system, the optimal regulating amount of all the actuators is merely calculated. Nevertheless, there are a large amount of incongruous actuator group behaviors which have a bad influence on flatness quality in the actual application process [19-21]. Therefore, in response to the above questions, a collaboration strategy based on conflict resolution for the flatness actuator group has been proposed in this paper. On the basis of the original flatness control system, the coordination between the actuator group is made achievable according to the matching degree between regulating characteristics of flatness actuator and flatness defect.

\section{Flatness Actuator Regulating Characteristics}

Different types of flatness actuator have complex differences in the effect of strip flatness [22]. In Figure 1, work roll bending, intermediate roll bending, and intermediate roll shifting have the ability to eliminate symmetrical flatness defect. Work roll tilting has the ability to eliminate asymmetric flatness defect. Work roll bending, work roll tilting, and intermediate roll shifting are in high sensitivity. Intermediate roll bending is in low sensitivity.

The characteristic of flatness actuator in high sensitivity is that it can cause huge flatness changes with very little adjustment. The effectiveness of the flatness control system has an important influence on the quality of the strip flatness. In the process of eliminating flatness defects, high effectiveness can be maintained through flatness actuator in high sensitivity. Simultaneously, it works with flatness actuator in low sensitivity to improve profile control accuracy.

2.1. External Evaluation Function. Through the external evaluation function, we can determine whether the effect of eliminating flatness defect meets the requirement. The expression of external evaluation function is as follows:

$$
\begin{aligned}
J= & \sum_{i=1}^{n_{1}}\left[g_{i}\left(\left(\operatorname{mes}_{i}-\operatorname{ref}_{i}\right)-f_{i}\right)\right]^{2} \\
f_{i}= & \Delta u_{\mathrm{WB}} \cdot \operatorname{Eff}_{\mathrm{WB}}(i)+\Delta u_{\mathrm{IB}} \cdot \operatorname{Eff}_{\mathrm{IB}}(i)+\Delta u_{\mathrm{IS}} \cdot \operatorname{Eff}_{\mathrm{IS}}(i) \\
& +\Delta u_{\mathrm{WT}} \cdot \operatorname{Eff}_{\mathrm{WT}}(i),
\end{aligned}
$$

where $n_{1}$ is the number of measuring sections. $g_{i}$ is the weight factor. mes ${ }_{i}$ is the measuring flatness. ref $_{i}$ is the setting flatness. $J$ is the external evaluation function. $\Delta u_{\mathrm{WB}}$ is the adjustment of work roll bending. $\mathrm{Eff}_{\mathrm{WB}}$ is the regulating efficiency factor of work roll bending. $\Delta u_{\mathrm{IB}}$ is the adjustment of intermediate roll bending. Eff $_{\mathrm{IB}}$ is the regulating efficiency factor of intermediate roll bending. $\Delta u_{\mathrm{IS}}$ is the adjustment of intermediate roll shifting. Eff IS $_{\text {is }}$ the regulating efficiency factor of intermediate roll shifting. $\Delta u_{\mathrm{WT}}$ is the adjustment of work roll tilting. Eff $\mathrm{WT}_{\mathrm{WT}}$ is the regulating efficiency factor of work roll tilting. $f_{i}$ is the flatness deviation eliminated by actuator.

2.2. External Constraint Condition. The external constraint condition is determined according to the upper and lower limit of the flatness actuator. The expression of external constraint condition is as follows:

$$
\begin{gathered}
l_{\mathrm{WB}} \leq v_{\mathrm{WB}}\left(n_{2}+1\right)=v_{\mathrm{WB}}\left(n_{2}-1\right)+\Delta u_{\mathrm{WB}}\left(n_{2}\right) \leq u_{\mathrm{WB}}, \\
l_{\mathrm{IB}} \leq v_{\mathrm{IB}}\left(n_{2}+1\right)=v_{\mathrm{IB}}\left(n_{2}-1\right)+\Delta u_{\mathrm{IB}}\left(n_{2}\right) \leq u_{\mathrm{IB}}, \\
l_{\mathrm{IS}} \leq v_{\mathrm{IS}}\left(n_{2}+1\right)=v_{\mathrm{IS}}\left(n_{2}-1\right)+\Delta u_{\mathrm{IS}}\left(n_{2}\right) \leq u_{\mathrm{IS}}, \\
l_{\mathrm{WT}} \leq v_{\mathrm{WT}}\left(n_{2}+1\right)=v_{\mathrm{WT}}\left(n_{2}-1\right)+\Delta u_{\mathrm{WT}}\left(n_{2}\right) \leq u_{\mathrm{WT}},
\end{gathered}
$$

where $\Delta u_{\mathrm{WB}}\left(n_{2}\right)$ is the adjustment of work roll bending in the $n_{2}$ cycle. $v_{\mathrm{WB}}\left(n_{2}-1\right)$ is the actual value of work roll bending in the $n_{2}-1$ cycle. $v_{\mathrm{WB}}\left(n_{2}+1\right)$ is the actual value of work roll bending in the $n_{2}+1$ cycle. $\Delta u_{\mathrm{WB}}\left(n_{2}\right)$ is the adjustment of intermediate roll bending in the $n_{2}$ cycle. $v_{\mathrm{IB}}\left(n_{2}-1\right)$ is the actual value of intermediate roll bending in the $n_{2}-1$ cycle. $v_{\mathrm{IB}}\left(n_{2}+1\right)$ is the actual value of intermediate roll bending in the $n_{2}+1$ cycle. $\Delta u_{\mathrm{IS}}\left(n_{2}\right)$ is the adjustment of intermediate roll shifting in the $n_{2}$ cycle. $v_{\text {IS }}\left(n_{2}-1\right)$ is the actual value of intermediate roll shifting in the $n_{2}-1$ cycle. $v_{\text {IS }}\left(n_{2}+1\right)$ is the actual value of intermediate roll shifting in the $n_{2}+1$ cycle. $\Delta u_{\mathrm{WT}}\left(n_{2}\right)$ is the adjustment of work roll tilting in the $n_{2}$ cycle. $v_{\mathrm{WT}}\left(n_{2}-1\right)$ is the actual value of work roll tilting in the $n_{2}-1$ cycle. $v_{\mathrm{WT}}\left(n_{2}+1\right)$ is the actual value of work roll tilting in the $n_{2}+$ 1 cycle. $u_{\mathrm{WB}}$ is the upper limit of work roll bending. It represents the maximum value that the work roll bending can output. $l_{\mathrm{WB}}$ is the lower limit of work roll bending. It represents the minimum value that the work roll bending can output. $u_{\mathrm{IB}}$ is the upper limit of intermediate roll bending. It represents the maximum value that the intermediate roll bending can output. $l_{\mathrm{IB}}$ is the lower limit of intermediate roll bending. It represents the minimum value that the intermediate roll bending can output. $u_{\mathrm{IS}}$ is the upper limit of intermediate roll shifting. It represents the maximum value that the intermediate roll shifting can output. $l_{\mathrm{IS}}$ is the lower limit of intermediate roll shifting. It represents the minimum value that the intermediate roll shifting can output. $u_{\mathrm{WT}}$ is the upper limit of work roll tilting. It represents the maximum value that the work roll tilting can output. $l_{\mathrm{WT}}$ is the lower limit of work roll tilting. It represents the minimum value that the work roll tilting can output.

\subsection{Actual Flatness Condition Discriminating Factor.} There are three coefficients: linear coefficient, quadratic coefficient, and edge coefficient. And the role of virtual flatness curve is that the local condition of actual flatness can be described quantitatively by these coefficients. The expression of virtual flatness curve $T(j)$ is as follows: 


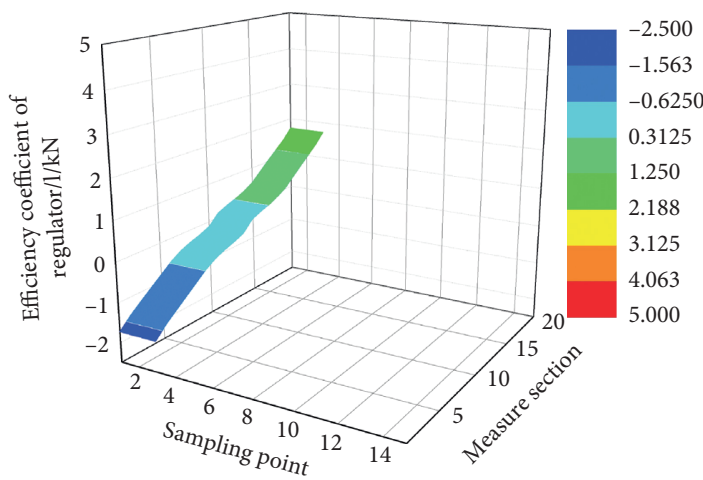

(a)

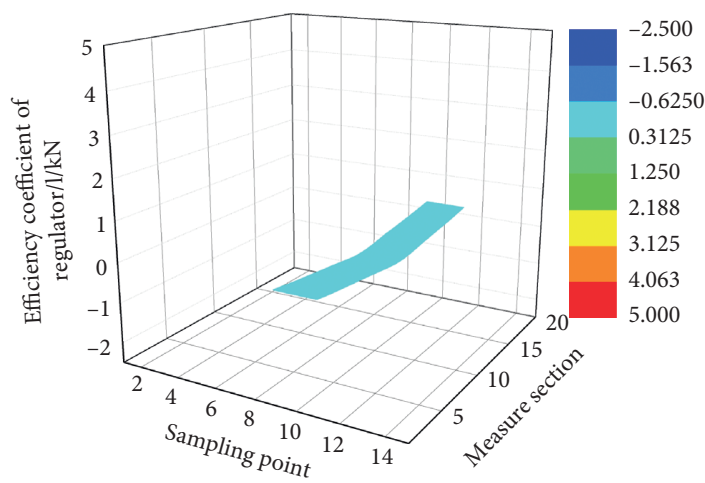

(c)

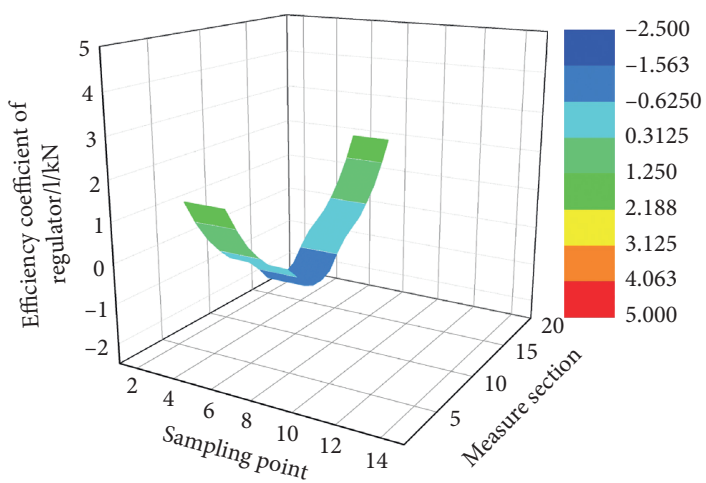

(b)

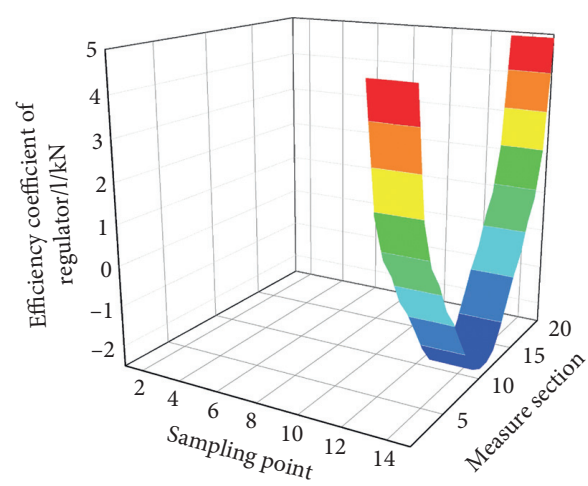

(d)

Figure 1: The regulating efficiency of regulating actuator. (a) The regulating efficiency of work roll tilting. (b) The regulating efficiency of work roll bending. (c) The regulating efficiency of intermediate roll bending. (d) The regulating efficiency of intermediate roll shifting.

$T\left(j, X_{-} 1, X_{-} 2, X_{-} 3\right)=$

$$
\left\{\begin{array}{l}
\left(\frac{j}{m_{3}-1}-0.5\right) X_{-} 1+\left(\left(\frac{2 j}{m_{3}-1}-1\right)^{2}-\frac{m_{3}+1}{3\left(m_{3}-1\right)}\right) X_{-} 2+\left(1-\frac{3}{m_{3}}\right) X_{-} 3, \quad j=0 \text { or } j=m_{3}-1, \\
\left(\frac{j}{m_{3}-1}-0.5\right) X_{-} 1+\left(\left(\frac{2 j}{m_{3}-1}-1\right)^{2}-\frac{m_{3}+1}{3\left(m_{3}-1\right)}\right) X_{-} 2+\left(0.5-\frac{3}{m_{3}}\right) X_{-} 3, \quad j=1 \text { or } j=m_{3}-2, \\
\left(\frac{j}{m_{3}-1}-0.5\right) X_{-} 1+\left(\left(\frac{2 j}{m_{3}-1}-1\right)^{2}-\frac{m_{3}+1}{3\left(m_{3}-1\right)}\right) X_{-} 2+\left(-\frac{3}{m_{3}}\right) X_{-} 3, \quad 2 \leq j \leq m_{3}-3,
\end{array}\right.
$$

where $X_{-} 1$ is the linear coefficient of virtual flatness curve. $X_{-} 2$ is the quadratic coefficient of virtual flatness curve. $X_{-} 3$ is the edge coefficient of virtual flatness curve. $m_{3}$ is the number of measuring sections occupied by strip. Its range is from 1 to $38 . T(j)$ is the virtual flatness in $j$ section.

The actual flatness condition discriminating factor includes the single-wave distinguishing factor $X_{-} 1_{-} e$, the symmetrical distinguishing factor $X_{\_} 2_{-} e$, and edge distinguishing factor $X_{-} 3_{-} e$. The actual flatness condition discriminating factor is plugged into expression of virtual flatness curve and $T\left(j, X_{-} 1_{-} e, X_{-} 2_{-} e, X_{-} 3_{-} e\right)$ is achieved. The mean square error is calculated between $T\left(j, X_{-} 1_{-} e, X_{-} 2_{-} e, X_{-} 3_{-} e\right)$ and the actual flatness $M(j)$. When the mean square error reaches the minimum value within the constraints $l l_{1} \leq X_{-} 1_{-} e \leq u l_{1}, \quad l l_{2} \leq X_{-} 2_{-} e \leq u l_{2}$, and $l l_{3} \leq X_{-} 3_{-} e \leq u l_{3}, T\left(j, X_{-} 1_{-} e, X_{-} 2_{-} e, X_{-} 3_{-} e\right)$ is equivalent to the actual flatness $M(j)$. The expression of calculating actual flatness condition discriminating factor is as follows: 


$$
\begin{array}{ll}
\min & \sum_{j=0}^{m_{3}-1}\left(M(j)-T\left(j, X_{-} 1_{-} e, X_{-} 2_{-} e, X_{-} 3_{-} e\right)\right)^{2} \\
\text { s.t. } & l_{1} \leq X_{-} 1_{-} e \leq u_{1} \\
& l_{2} \leq X_{-} 2_{-} e \leq u_{2} \\
& l_{3} \leq X_{-} 3_{-} e \leq u_{3},
\end{array}
$$

where $M(j)$ is the actual flatness in $j$ section. $X_{-} 1_{-} e$ is the single-wave distinguishing factor. $X_{-} 2_{-} e$ is the symmetrical distinguishing factor. $X_{-} 3_{-} e$ is the edge distinguishing factor. $u_{1}$ is the upper limit of single-wave distinguishing factor. It represents the maximum value of single-wave distinguishing factor. $l_{1}$ is the lower limit of single-wave distinguishing factor. It represents the minimum value of single-wave distinguishing factor. $u_{2}$ is the upper limit of symmetrical distinguishing factor. It represents the maximum value of symmetrical distinguishing factor. $l_{2}$ is lower limit of symmetrical distinguishing factor. It represents the minimum value of symmetrical distinguishing factor. $u_{3}$ is the upper limit of edge distinguishing factor. It represents the maximum value of edge distinguishing factor. $l_{3}$ is the lower limit of edge distinguishing factor. It represents the minimum value of edge distinguishing factor.

2.4. Flatness Actuator Group Collaboration Strategy. Not only can the analysis of actual flatness condition be conducted in real time but also the reasonable adjustment strategy is intelligently selected in the intelligent flatness control system [23-25]. As a consequence, the overall regulation capacity of flatness adjustment actuator after the combination is made to match with the flatness defect.

When the single-wave distinguishing factor is greater than the upper limit of linear reasonable range, the local flatness status is single wave in the drive side. When the single-wave distinguishing factor is less than the lower limit of linear reasonable range, the local flatness status is single wave in the operating side. When the single-wave distinguishing factor is within the linear reasonable range, the local flatness status is symmetrical between the drive side and the operating side. If the actual flatness status is unsymmetrical, the following are the regulation strategies: The adjustment of work roll tilting is relatively big. If the actual flatness status is symmetrical, the following are the regulation strategies: The adjustment of work roll tilting is relatively small.

When the expression $X_{-} 1_{-} e>u_{l}$ or $X_{-} 1_{-} e<l_{l}$ is satisfied, the following are the regulation strategy $A$ :

$$
\begin{aligned}
& \Delta u_{\mathrm{WT}}>\Delta u_{\mathrm{WB}}, \\
& \Delta u_{\mathrm{WT}}>\Delta u_{\mathrm{IB}}, \\
& \Delta u_{\mathrm{WT}}>\Delta u_{\mathrm{IS}},
\end{aligned}
$$

where $u_{l}$ is the upper limit of linear reasonable range. It represents critical value of single wave in the drive side. $l_{l}$ is the lower limit of linear reasonable range. It represents the critical value of single wave in the operating side.
When the expression $l_{l}<X_{-} 1_{-} e<u_{l}$ is satisfied, the following are the regulation strategy $B$ :

$$
\begin{aligned}
& \Delta u_{\mathrm{WT}}<\Delta u_{\mathrm{WB}}, \\
& \Delta u_{\mathrm{WT}}<\Delta u_{\mathrm{IB}}, \\
& \Delta u_{\mathrm{WT}}<\Delta u_{\mathrm{IS}} .
\end{aligned}
$$

When the symmetrical distinguishing factor is greater than the upper limit of quadratic reasonable range, the local flatness status is severe central wave. When the symmetrical distinguishing factor is less than the lower limit of quadratic reasonable range, the local flatness status is severe bilateral wave. When the symmetrical distinguishing factor is within the quadratic reasonable range, the local flatness status is slight central wave or bilateral wave. If the severe flatness defect appears in rolling, the top priority is the speed of eliminating flatness deviation. Therefore, the following are the regulation strategies: The adjustment of work roll bending is relatively big, while the adjustment of intermediate roll bending is relatively small. If the slight flatness defect appears in rolling, the top priority is the accuracy of eliminating flatness deviation. Therefore, the following are the regulation strategies: The adjustment of work roll bending is relatively small, while the adjustment of intermediate roll bending is relatively big.

When the expression $X_{-} 2_{-} e>u_{q}$ or $X_{-} 2_{-} e<l_{q}$ is satisfied, the following are the regulation strategy $\mathrm{C}$ :

$$
\Delta u_{\mathrm{WB}}>\Delta u_{\mathrm{IB}}
$$

where $u_{q}$ is the upper limit of quadratic reasonable range. It represents critical value of severe central wave. $l_{q}$ is the lower limit of quadratic reasonable range. It represents critical value of severe bilateral wave.

When the expression $l_{q}<X_{-} 2_{-} e<u_{q}$ is satisfied, the following are the regulation strategy $D$ :

$$
\Delta u_{\mathrm{WB}}<\Delta u_{\mathrm{IB}} .
$$

When the edge distinguishing factor is greater than the upper limit of edge reasonable range, the local flatness status is severe edge drop. When the edge distinguishing factor is less than the lower limit of edge reasonable range, the local flatness status is tight flatness in the outermost section. When the edge distinguishing factor is within the edge reasonable range, the local flatness status is slight edge drop. If the severe edge drop appears in rolling, the following are the regulation strategies: The adjustment of intermediate roll shifting is relatively big. If the slight edge drop appears in rolling, the following are the regulation strategies: The adjustment of intermediate roll shifting is relatively small.

When the expression $X_{-} 3_{-} e>u_{e}$ or $X_{-} 3_{-} e<l_{e}$ is satisfied, the following are the regulation strategy $\mathrm{E}$ :

$$
\begin{aligned}
& \Delta u_{\mathrm{IS}}>\Delta u_{\mathrm{WB}}, \\
& \Delta u_{\mathrm{IS}}>\Delta u_{\mathrm{IB}},
\end{aligned}
$$

where $u_{e}$ is the upper limit of edge reasonable range. $l_{e}$ is the lower limit of edge reasonable range. 
When the expression $l_{e}<X_{-} 3_{-} e<u_{e}$ is satisfied, the following are the regulation strategy $\mathrm{F}$ :

$$
\begin{aligned}
& \Delta u_{\mathrm{IS}}<\Delta u_{\mathrm{WB}}, \\
& \Delta u_{\mathrm{IS}}<\Delta u_{\mathrm{IB}} .
\end{aligned}
$$

Through collaboration strategy, the flatness control system can intelligently select the optimal adjusting mode according to the actual flatness status. The flowchart of collaboration strategy for flatness actuator group is shown in Figure 2.

The collaboration strategy for the flatness actuator group includes flatness analysis module, strategy matching module, and coordinated adjustment computing module. First of all, the method of calculating the equivalent flatness curve is used to extract the flatness defect characteristics for the measured flatness value. Secondly, the adjustment strategy that matches the actual flatness is selected by solving the flatness distinguishing factor. Finally, the Topkis-Veinott algorithm and genetic algorithm are jointly optimized to obtain the coordinated adjustment of the actuator group. The specific requirements of the strip steel flatness in the downstream process are different. Different specifications of strip steel flatness control accuracy are also different. Therefore, the determination of these coefficients requires comprehensive consideration of strip steel specifications and target flatness coefficients.

\subsection{Flatness Actuator Group Coordinated Adjustment.} The collaboration strategy strategies $\mathrm{A} \sim \mathrm{F}$ were originally formulated for different flatness conditions. When the flatness condition matches the adjustment strategy, the collaboration strategy can effectively avoid the uncoordinated regulating behaviors in the flatness actuator group. Every collaboration strategy can be called in a loop. When the flatness condition does not match the adjustment strategy, the current strategy is abandoned, and other strategies are selected based on the judgment conditions. The external evaluation function is considered as the objective function of calculating coordinated adjustment. The external constraint condition and the flatness actuator group collaboration strategy are seen together as constraint condition of calculating coordinated adjustment. The single-wave situation is taken as an example. The expression of calculating coordinated adjustment is as follows:

$$
\begin{array}{ll}
\min J & \\
& l_{\mathrm{WB}} \leq v_{\mathrm{WB}}\left(n_{2}-1\right)+\Delta u_{\mathrm{WB}}\left(n_{2}\right) \leq u l_{\mathrm{WB}} \\
& l_{\mathrm{IB}} \leq v_{\mathrm{IB}}\left(n_{2}-1\right)+\Delta u_{\mathrm{IB}}\left(n_{2}\right) \leq u l_{\mathrm{IB}} \\
& l_{\mathrm{IS}} \leq v_{\mathrm{IS}}\left(n_{2}-1\right)+\Delta u_{\mathrm{IS}}\left(n_{2}\right) \leq u l_{\mathrm{IS}} \\
\text { s.t. } & l_{\mathrm{WT}} \leq v_{\mathrm{WT}}\left(n_{2}-1\right)+\Delta u_{\mathrm{WT}}\left(n_{2}\right) \leq u l_{\mathrm{WT}} \\
& \Delta u_{\mathrm{WT}}>\Delta u_{\mathrm{WB}} \\
& \Delta u_{\mathrm{WT}}>\Delta u_{\mathrm{IB}} \\
& \Delta u_{\mathrm{WT}}>\Delta u_{\mathrm{IS}} .
\end{array}
$$

\section{Coordinated Algorithm Based on Topkis- Veinott and Genetic Algorithm}

In order to achieve actual flatness condition discriminating factor and flatness actuator group coordinated adjustment, the coordinated algorithm is proposed based on TopkisVeinott and genetic algorithm. Its main advantage is as follows.

In the coordinated algorithm, both the searching definiteness and randomness are taken into account. The probabilistic search is adopted in the transfer direction of search point. And the deterministic search is adopted in transfer relation of search point. This algorithm design can provide high search speed and flexibility, and the situation of missing optimal point can be avoided. Moreover, in the coordinated algorithm, multipoint searching and singlepoint searching are simultaneously carried through. This algorithm design can provide a more extensive search scope and more abundant search information.

Expression (4) and expression (11) are equivalent to the following function optimization problem:

$$
\begin{array}{ll}
\min & f_{T V}\left(\bar{x}_{T V}\right) \\
\text { s.t. } & g_{T V i}\left(\bar{x}_{T V}\right) \geq 0 \quad i=1,2, \ldots, m_{T V},
\end{array}
$$

where $f_{T V}\left(\bar{x}_{T V}\right)$ is the objective function of function optimization problem. $g_{T V i}\left(\bar{x}_{T V}\right) \geq 0$ is nonlinear and linear inequality constraints of function optimization problem. $m_{T V}$ is the number of nonlinear and linear inequality constraints. $\bar{x}_{T V}=\left(x_{T V 1}, x_{T V 2}, \ldots, x_{T V N_{T V}}\right)^{T}$ is the variable vector. $N_{T V}$ is the number of variables.

The flowchart of coordinated algorithm is shown in Figure 3. Its step is as follows:

(1) $\bar{x}_{T V}^{(0)}$ is selected as the initial point of coordinated algorithm. The expression $\varepsilon_{T V}>0$ and the expression $k_{T V}=0$ are satisfied. $\bar{x}_{T V}^{(0)}$ is the initial point of coordinated algorithm. $\varepsilon_{T V}$ is the iteration accuracy of coordinated algorithm. $k_{T V}$ is the iteration number of coordinated algorithms.

(2) The programming problem $\mathrm{A}$ is established as follows:

$$
\begin{array}{ll}
\min & f_{T V}\left(\bar{P}_{T V}, y_{T V}\right)=y_{T V} \\
\text { s.t. } & \nabla f_{T V}\left(\bar{x}_{T V}\right)^{T} \bar{P}_{T V}-y_{T V} \leq 0 \\
& -\nabla g_{T V i}\left(\bar{x}_{T V}\right)^{T} \bar{P}_{T V}-y_{T V} \leq g_{T V i}\left(\bar{x}_{T V}\right) \quad i=1,2, \ldots, m_{T V} \\
& -1 \leq P_{T V} \leq 1 \quad j=1,2, \ldots, n_{T V} .
\end{array}
$$

The optimal solution of programming problem $\mathrm{A}$ is $\left(\bar{P}_{T V}^{\left(k_{T V}\right)}, y_{T V}^{\left(k_{T V}\right)}\right)^{T}$, and it is the result after $k_{T V}$ iterations. $\bar{x}_{T V}$ is a point in the iterative process. $\bar{P}_{T V}=$ $\left(P_{T V 1}, P_{T V 2}, \ldots, P_{T V n_{T V}}\right)^{T}$ is the descent direction vector of point $\bar{x}_{T V} \cdot n_{T V}$ is the dimension of vector $\bar{P}_{T V} . \quad y_{T V}=\max \left\{\nabla f_{T V}\left(\bar{x}_{T V}\right)^{T} \bar{P}_{T V},-\nabla g_{T V i}\left(\bar{x}_{T V}\right)\right.$ $\left.\bar{P}_{T V}, i \in I_{T V}\right\}$ is the decision parameter of terminating iteration. $\nabla f_{T V}\left(\bar{x}_{T V}\right)$ is the partial derivative 


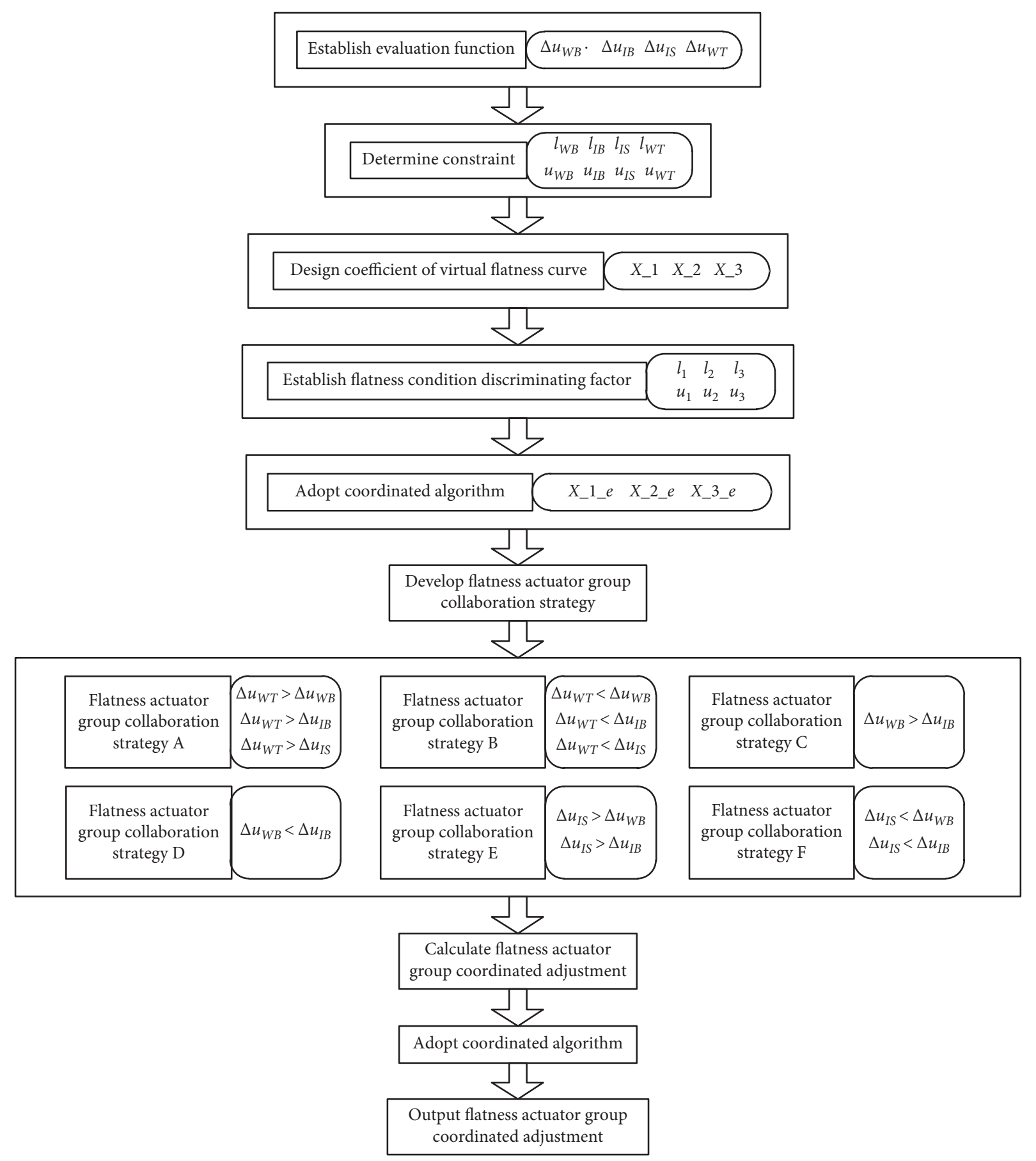

Figure 2: The flowchart of collaboration strategy for flatness actuator group.

of objective function. $\nabla g_{T V i}\left(\bar{x}_{T V}\right)$ is the partial derivative of inequality constraints.

(3) The programming problem A is transformed into an equivalent programming problem $\mathrm{B}$ :

$$
\begin{aligned}
& \min f_{L P}\left(x_{i}\right), \quad 1 \leq i \leq N \\
& \text { s.t. } \quad\left\{\begin{array}{l}
h_{j}\left(x_{i}\right) \geq 0 \\
a_{i} \leq x_{i} \leq b_{i}
\end{array}, \quad 1 \leq j \leq M .\right.
\end{aligned}
$$

$f_{L P}\left(x_{i}\right)$ is the objective function of programming problem B. $\left(x_{1}, x_{2}, \ldots, x_{N}\right)^{T}=\left(P_{T V 1}, P_{T V 2}, \ldots\right.$, $\left.P_{T V n_{T V}}\right)^{T}$ is the variable vector of programming problem B. $N$ is the number of variables. $h_{j}\left(x_{i}\right)$ is inequality constraints. $M$ is the number of inequality constraints. $a_{i}$ is the lower limit of constrained domain. $b_{i}$ is the upper limit of constrained domain. 


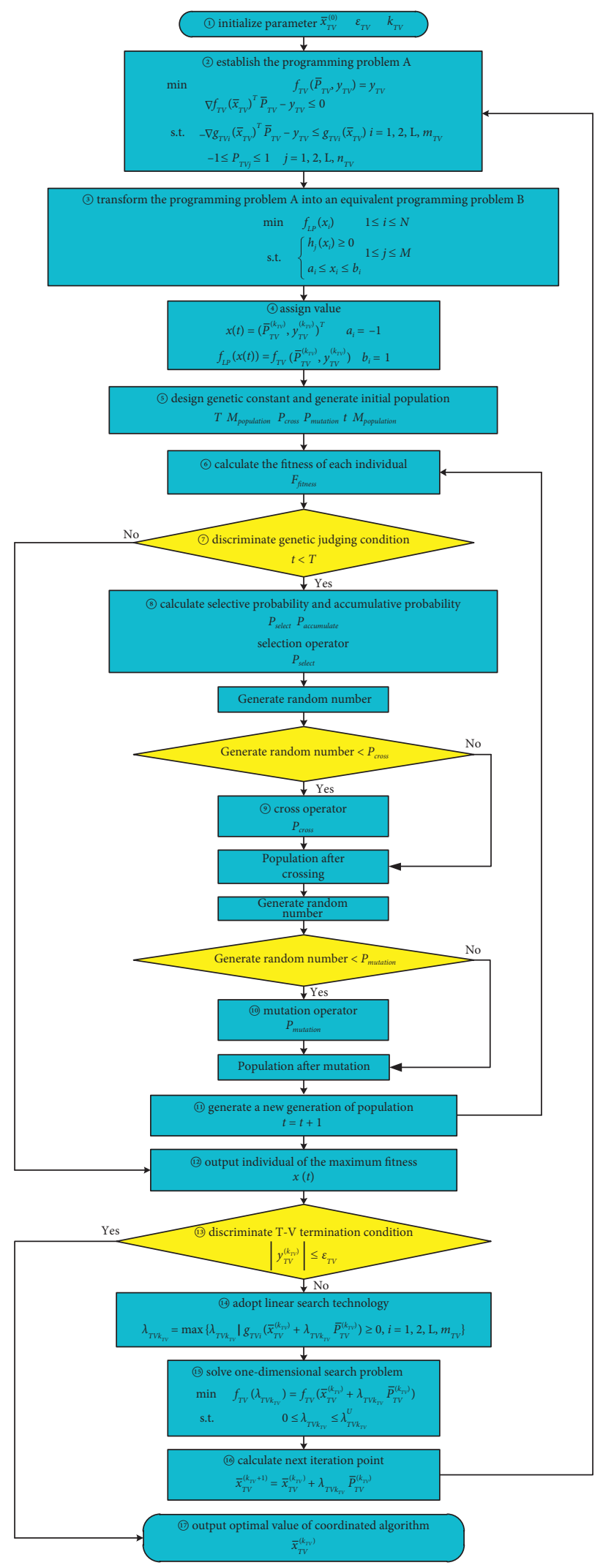

FIGURE 3: The flowchart of coordinated algorithm. 
(4) Set $\quad x(t)=\left(\bar{P}_{T V}^{\left(k_{T V}\right)}, y_{T V}^{\left(k_{T V}\right)}\right)^{T}$ and $f_{L P}(x(t))=$ $f_{T V}\left(\bar{P}_{T V}^{\left(k_{T V}\right)}, y_{T V}^{\left(k_{T V}\right)}\right) . a_{i}$ is set to $-1 . b_{i}$ is set to 1 . An initial population is generated.

(5) The maximum generation $T$, population number $M_{\text {population }}$, cross probability $P_{\text {cross }}$, and mutation probability $P_{\text {mutation }}$ are assigned to a starting value.

(6) The fitness $F_{\text {fitness }}$ of each individual in the population is calculated.

(7) When the condition $t<T$ is satisfied, turn to (8). When the condition $t<T$ is not satisfied, turn to (13).

(8) The selective probability $P_{\text {select }}$ and accumulative probability $P_{\text {accumulate }}$ of each individual in the population are calculated. A random number in interval $[0,1]$ is generated. If the random number is less than $P_{\text {accumulate }}(1)$, the first individual is selected. If the random number is more than $P_{\text {accumulate }}(k-1)$ and less than $P_{\text {accumulate }}(k)$, the $k$ individual is selected. The best individuals get multiple copies. Medium individual keeps steady. The worst individual is dead. $M_{\text {population }}$ individuals are randomly selected on the basis of selective probability $P_{\text {select }}$. The copies of the best individual

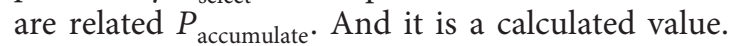
The medium individual is an individual who has a higher fitness than the eliminated individual and has not reached the optimal fitness. It is the medium one after sorting all the individuals as their fitness values.

(9) A random number in interval $[0,1]$ is generated. If the random is less than cross probability $P_{\text {cross }}$, the individual is crossed. The individuals are selected from the population for mating. The offspring goes into the new population. The unmated individuals are directly copied into the new population.

(10) The mutation opportunity of each individual is equipotent. A random number in interval $[0,1]$ is generated. When the random is less than $P_{\text {mutation}}$, the individual is mutated. The individuals are selected for mutating in the new population. The original individual is replaced by the individual after mutating.

(11) Set $t=t+1$. Turn to (6).

(12) The individual of the maximum $F_{\text {fitness }}$ is decoded. $x(t)$ after decoding is the optimal value. $x(t)$ is the optimal solution $\left(\bar{P}_{T V}^{\left(k_{T V}\right)}, y_{T V}^{\left(k_{T V}\right)}\right)^{T}$.

(13) When the terminal condition $|Z(k)|<\varepsilon_{Z}$ is satisfied, turn to (18). When the terminal condition $|Z(k)|<\varepsilon_{Z}$ is not satisfied, turn to (14).

(14) $\lambda_{T V k_{T V}}^{U}$ is the upper bound of the search step size factor in the $k_{T V}$ iteration. $\lambda_{T V k_{T V}}=\max$ $\left\{\lambda_{T V k_{T V}} \mid g_{T V i}\left(\bar{x}_{T V}^{\left(k_{T V}\right)}+\lambda \quad{ }_{T V k_{T V}} \bar{P}_{T V}^{\left(k_{T V}\right)}\right) \geq 0, \quad i=1,2\right.$, $\left.\ldots, m_{T V}\right\}$ is the search step size factor in the $k_{T V}$ iteration. $\lambda_{T V k_{T V}}$ can be deachieved by linear search technology.
(15) The following one-dimensional search problem is solved:

$\min f_{T V}\left(\lambda_{T V k_{T V}}\right)=f_{T V}\left(\bar{x}_{T V}^{\left(k_{T V}\right)}+\lambda_{T V k_{T V}} \bar{P}_{T V}^{\left(k_{T V}\right)}\right)$

s.t. $\quad 0 \leq \lambda_{T V k_{T V}} \leq \lambda_{T V k_{T V}}^{U}$.

(16) The expression $\bar{x}_{T V}^{\left(k_{T V}+1\right)}=\bar{x}_{T V}^{\left(k_{T V}\right)}+\lambda_{T V k_{T V}} \bar{P}_{T V}^{\left(k_{T V}\right)}$ is calculated. Then, we can turn to (2).

(17) $\bar{x}_{T V}^{\left(k_{T V}\right)}$ is the optimal value. Output $\bar{x}_{T V}^{\left(k_{T V}\right)}$.

3.1. Field Test Experiment. The collaboration strategy for flatness actuator group is adopted to a flatness control system of a $1450 \mathrm{~mm}$ five-stand cold rolling mill. The $\mathrm{C}$ language program is written according to the collaboration strategy; the custom function block for the coordinated algorithm that can be called directly in Step 7 environment is generated through the Function Block generator tool. The conventional method is to use the least square method to solve the optimal adjustment amount of each flatness actuator. However, the strategy of flatness actuator is not matched to the actual flatness of the strip. The collaboration strategy is encapsulated into the coordinated regulating module and it is embedded into the original flatness control system. The main hardware of SIMATIC TDC is shown in Table 1 . The initial value of coordinated algorithm parameter is shown in Table 2.

The algorithm comparison chart is shown in Figure 4. The flatness control system equipment distribution is shown in Figure 5. The operation interface of the flatness control system is shown in Figure 6. The $1450 \mathrm{~mm}$ five-stand cold rolling mill production line is shown in Figure 7.

GA is done in a probabilistic way, but this randomness may cause nonconvergence. Topkis-Veinott algorithm uses a deterministic search method. The transfer from one search point to another has a certain transfer direction and transfer relationship. The coordinated algorithm takes into account the determinism and randomness of search. The probabilistic search technology is used for the transfer direction of the search point. The deterministic search technology is used for the transfer relationship of search point. This ensures high search speed and flexibility. And it avoids the situation where the best point cannot be searched all the time. In Figure 4 , the objective function value of GA maintains a decreasing trend in the initial iteration stage. However, as the number of iterations increases, the objective function value of GA fluctuates greatly. Topkis-Veinott algorithm can ensure the trend of continuous reduction of the objective function value. But its number of iterations is relatively large. The value of the objective function of the coordinated algorithm maintains a decreasing trend. And the convergence is reached in a small number of iterations.

The flatness detecting device is $\mathrm{ABB}$ shapemeter roll. The flatness regulating device of the six-roll UCM rolling mill includes work roll tilting, work roll bending, intermediate roll bending, intermediate roll shifting, and selective work 
TABLE 1: The main hardware of SIMATIC TDC.

\begin{tabular}{lcc}
\hline TDC hardware & Product model & Function \\
\hline Rack & UR5213 & 21 slots are provided \\
Central processing unit & CPU551 & High-performance closed-loop control is achieved \\
I/O template & SM500 & Analog and digital input interfaces are provided \\
Communication template & CP51M1 & Interrack Ethernet communication and WinCC communication are provided \\
Program memory module & MC500 & Storing handlers and hardware configurations are provided \\
\hline
\end{tabular}

TABLE 2: The initial value of coordinated algorithm parameter.

\begin{tabular}{lcc}
\hline Variable name & Variable meaning & Variable value \\
\hline $\bar{x}_{T V}^{(0)}$ & Initial point of coordinated algorithm & $(0,0, \ldots, 0)$ \\
$\varepsilon_{T V}$ & Iteration accuracy of coordinated algorithm & $1 \times 10^{-9}$ \\
$T$ & Maximum generation & 1000 \\
$M_{\text {population }}$ & Population number & 100 \\
$P_{\text {cross }}$ & Cross probability & 0.6 \\
$P_{\text {mutation }}$ & Mutation probability & 0.07 \\
$a_{i}$ & Lower limit of constrained domain & -1 \\
$b_{i}$ & Upper limit of constrained domain & 1 \\
\hline
\end{tabular}

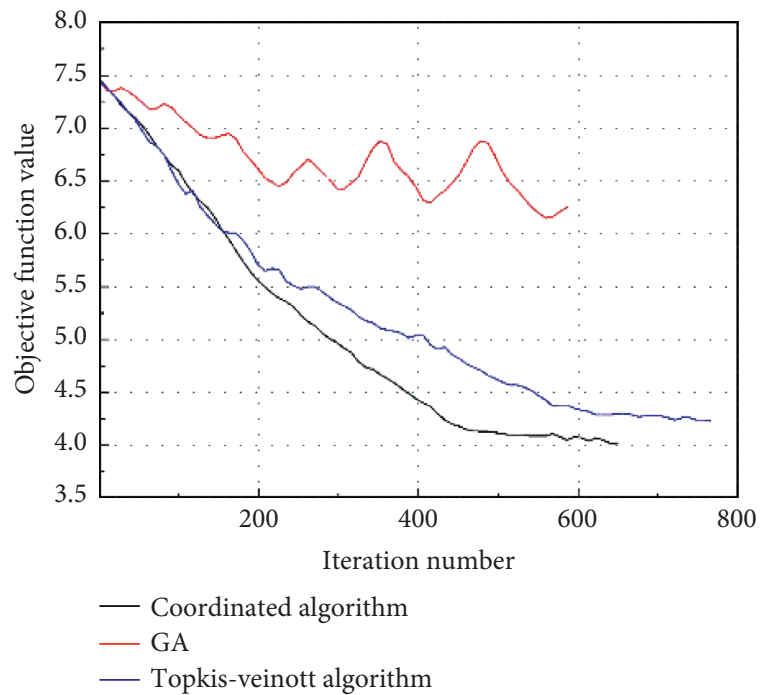

FIgURE 4: The algorithm comparison chart.

roll cooling. SIMATIC TDC controller communicates with HMI, PDA, and L2 server via Industrial Ethernet. The independent computer is used for monitoring and diagnostics of SIMATIC TDC controllers (Table 3).

\subsection{Flatness Control Effect of Different Rolling Speed.} When the rolling speed is different, the control effect with using the flatness actuator group collaboration strategy is compared with the control effect with using the conventional method. The experimental parameter of the flatness control effect test of different rolling speed is shown in Table 4. The flatness control effect of different rolling speed is shown in Figure 8. follows:

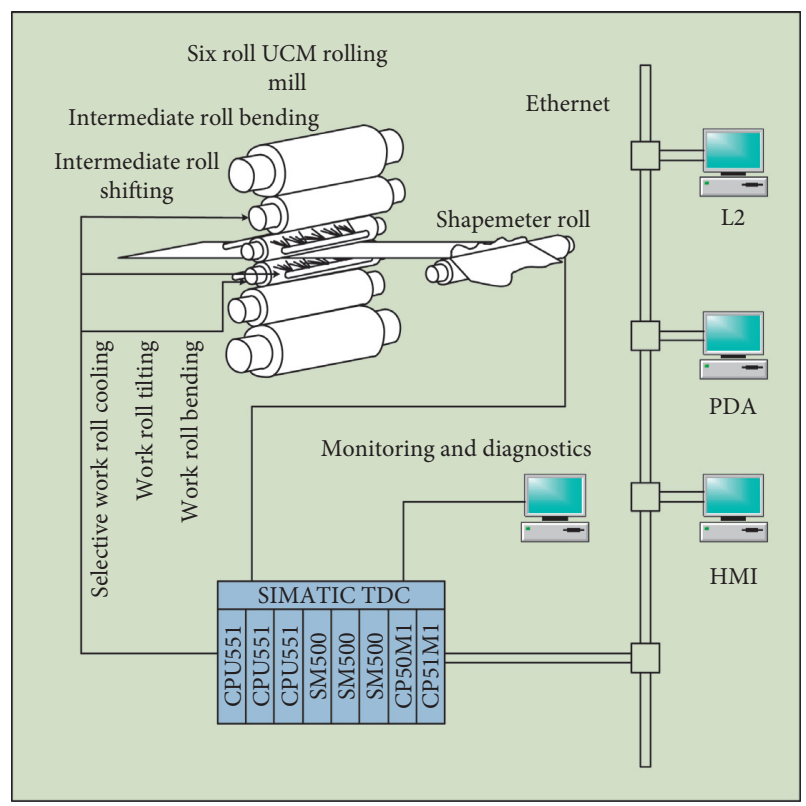

Figure 5: The flatness control system equipment distribution.

$$
c_{s}=\frac{\left(d_{1}-d_{2}\right)}{d_{1}}
$$

where $c_{s}$ is compensation efficiency of strip rolling speed. It represents the compensation efficiency for the flatness deviation caused by the speed change. $d_{1}$ is the average flatness deviation of $910 \mathrm{~m} / \mathrm{min}$ rolling speed with the conventional method. $d_{2}$ is the average flatness deviation of $1100 \mathrm{~m} / \mathrm{min}$ rolling speed with the conventional method.

In Figure 8, when the rolling speed is $910 \mathrm{~m} / \mathrm{min}$ and the control method is changed from conventional model to collaboration strategy model, the average flatness deviation is decreased in every measuring section. The maximum decreasing magnitude is $3.81 \mathrm{I}$. It indicates that if the wide 


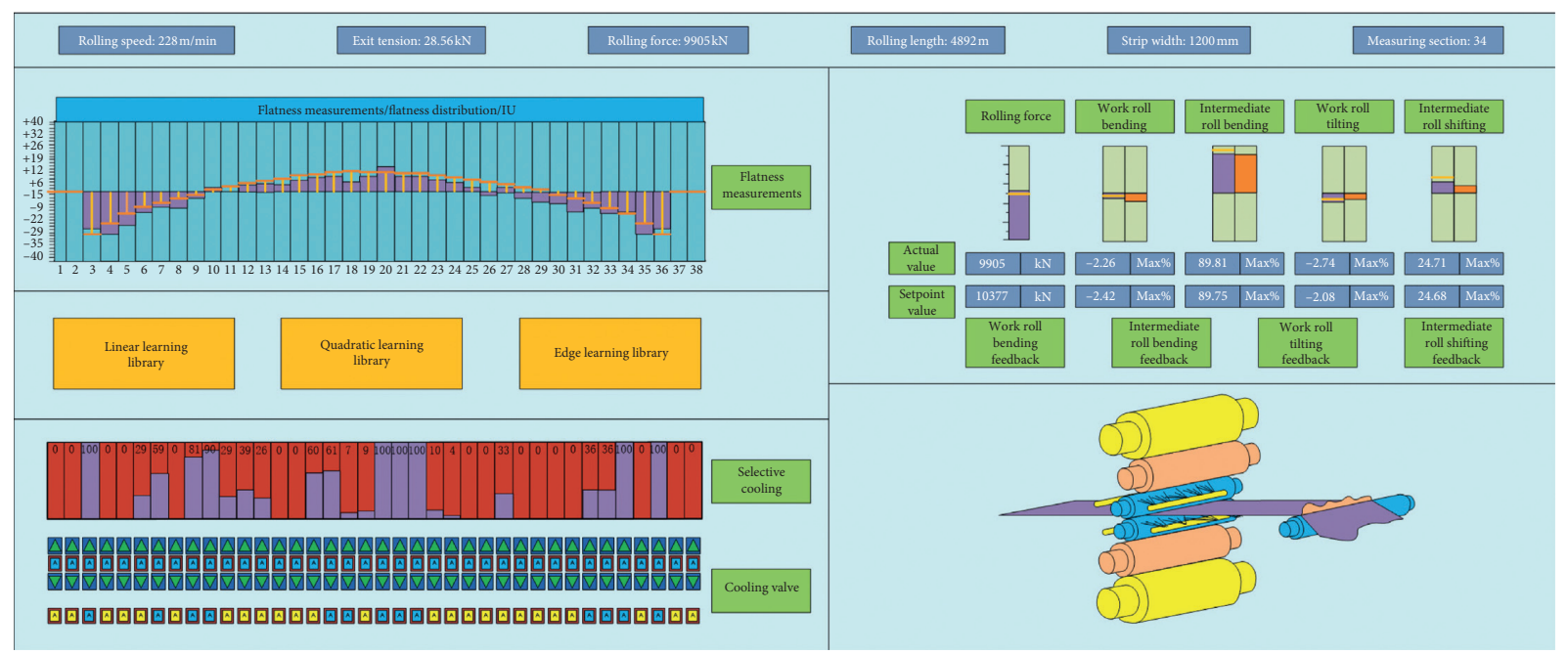

Figure 6: The operation interface of the flatness control system.

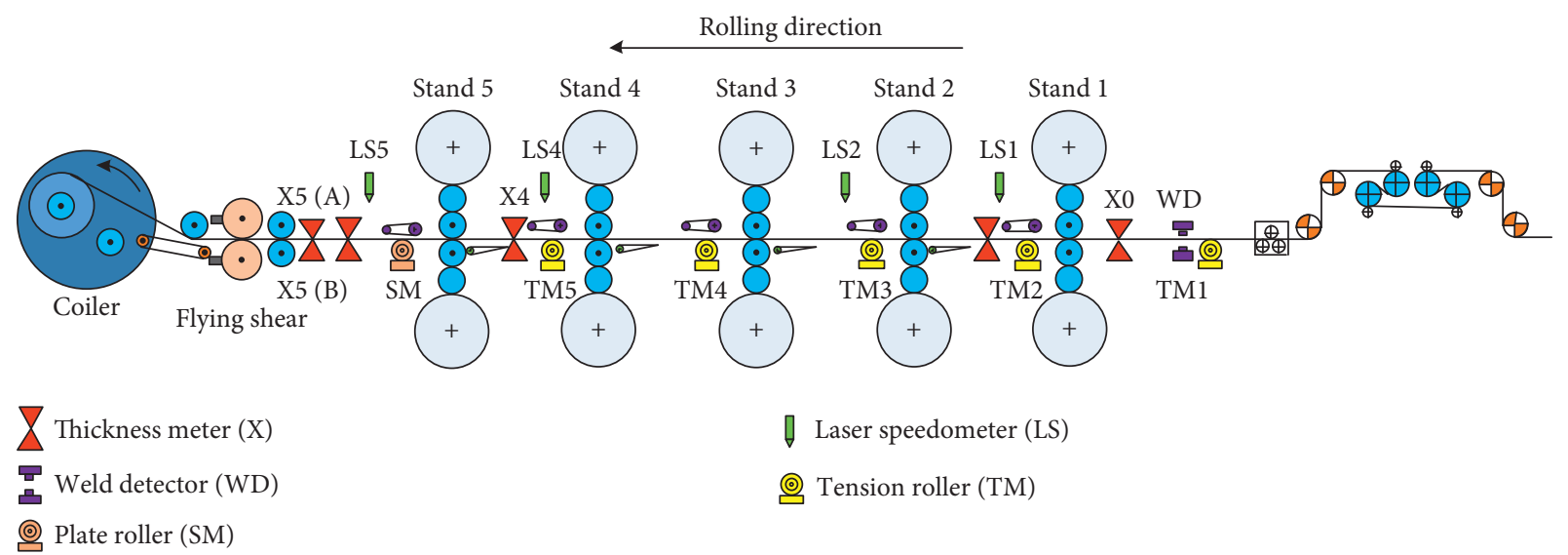

Figure 7: The $1450 \mathrm{~mm}$ five-stand cold rolling mill production line.

strip is rolled, the control effect of using collaboration strategy model is better than the control effect of using conventional model. When the conventional model is used and the rolling speed is changed from $1100 \mathrm{~m} / \mathrm{min}$ to $910 \mathrm{~m} /$ $\mathrm{min}$, the average flatness deviation is increased in every measuring section. The maximum increasing magnitude is 3.17 I. It indicates that if the conventional model is used, the control effect of low rolling speed is worse than control effect of high rolling speed. When the rolling speed is changed from $910 \mathrm{~m} / \mathrm{min}$ to $1100 \mathrm{~m} / \mathrm{min}$ and the control method is changed from collaboration strategy model to conventional model, the change of average flatness deviation is small. The maximum changing magnitude is $1.33 \mathrm{I}$. It indicates that the rolling speed can be compensated by using collaboration strategy model. The maximal compensation efficiency of strip rolling speed is $51.89 \%$.

\subsection{Flatness Control Effect of Different Rolling Force.} When the rolling force is different, the control effect with using the flatness actuator group collaboration strategy is compared with the control effect with using conventional method. The experimental parameter of the flatness control effect test of different rolling force is shown in Tables 5 and 6. The flatness control effect of different rolling force is shown in Figure 9.

The compensation efficiency of rolling force is as follows:

$$
c_{f}=\frac{\left(e_{1}-e_{2}\right)}{e_{1}},
$$

where $c_{f}$ is the compensation efficiency of rolling force. It represents the compensation efficiency for the flatness deviation caused by the change of rolling force. $e_{1}$ is the average flatness deviation of $8300 \mathrm{kN} \sim 8900 \mathrm{kN}$ with conventional method. $e_{2}$ is the average flatness deviation of $7700 \mathrm{kN} \sim 8300 \mathrm{kN}$ with conventional method.

In Figure 9, when the rolling force is $8300 \mathrm{kN} \sim 8900 \mathrm{kN}$ and the control method is changed from conventional model to collaboration strategy model, the average flatness deviation is decreased in every measuring section. The maximum decreasing magnitude is $2.52 \mathrm{I}$. It indicates that if the strip is rolled in large rolling force, the control effect of using collaboration strategy model is better than the control effect of using conventional model. When the conventional model is used and the rolling force is changed from 
TABLE 3: The average flatness deviation of different rolling speed.

\begin{tabular}{|c|c|c|c|}
\hline $\begin{array}{l}\text { Measure } \\
\text { segment }\end{array}$ & $\begin{array}{l}\text { Difference between the average flatness } \\
\text { deviation of } 910 \mathrm{~m} / \mathrm{min} \text { rolling speed } \\
\text { with conventional method and the } \\
\text { average flatness deviation of } 910 \mathrm{~m} / \mathrm{min} \\
\text { rolling speed with collaboration } \\
\text { strategy/I }\end{array}$ & $\begin{array}{l}\text { Difference between the average flatness } \\
\text { deviation of } 910 \mathrm{~m} / \mathrm{min} \text { rolling speed } \\
\text { with conventional method and the } \\
\text { average flatness deviation of } 1100 \mathrm{~m} / \\
\text { min rolling speed with conventional } \\
\text { method/I }\end{array}$ & $\begin{array}{l}\text { Absolute value of difference between the } \\
\text { average flatness deviation of } 910 \mathrm{~m} / \mathrm{min} \\
\text { rolling speed with collaboration strategy } \\
\text { and the average flatness deviation of } \\
1100 \mathrm{~m} / \mathrm{min} \text { rolling speed with } \\
\text { conventional method/I }\end{array}$ \\
\hline 1 & 3.81 & 1.95 & 0.30 \\
\hline 2 & 1.79 & 1.51 & 0.28 \\
\hline 3 & 2.13 & 2.24 & 0.10 \\
\hline 4 & 1.56 & 1.11 & 0.44 \\
\hline 5 & 1.20 & 1.32 & 0.11 \\
\hline 6 & 1.82 & 1.50 & 0.32 \\
\hline 7 & 1.03 & 1.59 & 0.55 \\
\hline 8 & 0.85 & 0.28 & 0.56 \\
\hline 9 & 1.62 & 1.90 & 0.27 \\
\hline 10 & 1.97 & 1.47 & 0.50 \\
\hline 11 & 0.94 & 1.61 & 0.67 \\
\hline 12 & 1.32 & 1.02 & 0.30 \\
\hline 13 & 1.54 & 1.98 & 0.44 \\
\hline 14 & 1.82 & 1.50 & 0.32 \\
\hline 15 & 1.00 & 0.57 & 0.42 \\
\hline 16 & 1.19 & 1.99 & 0.79 \\
\hline 17 & 1.60 & 2.12 & 0.52 \\
\hline 18 & 1.83 & 3.17 & 1.33 \\
\hline 19 & 1.22 & 1.52 & 0.30 \\
\hline 20 & 1.65 & 0.98 & 0.67 \\
\hline
\end{tabular}

TABLE 4: The experimental parameter of the flatness control effect test of different rolling speed.

\begin{tabular}{lcccc}
\hline Test number & Gauge/mm & Strip & Rolling speed $/ \mathrm{m} / \mathrm{min}$ & Strategy \\
\hline 1 & $2.2 \times 1250 \longrightarrow 0.28 \times 1250$ & DDQ & 1100 & Conventional method \\
2 & $2.2 \times 1250 \longrightarrow 0.28 \times 1250$ & DDQ & 910 & Collaboration strategy \\
3 & $2.2 \times 1250 \longrightarrow 0.28 \times 1250$ & DDQ & 910 & Conventional method \\
\hline
\end{tabular}

$7700 \mathrm{kN}-8300 \mathrm{kN}$ to $8300 \mathrm{kN} \sim 8900 \mathrm{kN}$, the average flatness deviation is increased in every measuring section. The maximum increasing magnitude is $2.71 \mathrm{I}$. It indicates that if the conventional model is used, the control effect of large rolling force is worse than control effect of little rolling force. When the rolling force is changed from $7700 \mathrm{kN}-8300 \mathrm{kN}$ to $8300 \mathrm{kN} \sim 8900 \mathrm{kN}$ and the control method is changed from conventional model to collaboration strategy model, the change of average flatness deviation is small. The maximum changing magnitude is $1.15 \mathrm{I}$. It indicates that the rolling force can be compensated by using collaboration strategy model. The maximal compensation efficiency of rolling force is $42.88 \%$.

\subsection{Flatness Control Effect of Different Rolling Reduction.} When the rolling reduction is different, the control effect with using the flatness actuator group collaboration strategy is compared with the control effect with using conventional method. The experimental parameter of the flatness control effect test of different rolling reduction is shown in Table 7. The flatness control effect of different rolling reduction is shown in Figure 10. follows:

The compensation efficiency of rolling reduction is as

$$
c_{r}=\frac{\left(f_{1}-f_{2}\right)}{f_{1}},
$$

where $c_{r}$ is the compensation efficiency of rolling reduction. It represents the compensation efficiency for the flatness deviation caused by the change of the rolling reduction. $f_{1}$ is the average flatness deviation of $32.96 \%$ rolling reduction with conventional method. $f_{2}$ is the average flatness deviation of $15.89 \%$ rolling reduction with conventional method (Table 8).

In Figure 10, when the rolling reduction is 32.96 and the control method is changed from conventional model to collaboration strategy model, the average flatness deviation is decreased in every measuring section. The maximum decreasing magnitude is $5.89 \mathrm{I}$. It indicates that if the strip is rolled in high rolling reduction, the control effect of using collaboration strategy model is better than the control effect of using conventional model. When the conventional model is used and the rolling reduction is changed from $15.89 \%$ to $32.96 \%$, the average flatness deviation is increased in every measuring section. The maximum increasing magnitude is $2.93 \mathrm{I}$. It indicates that if the conventional model is used, the control effect of high rolling reduction is worse than control effect of low rolling reduction. When the rolling reduction is 

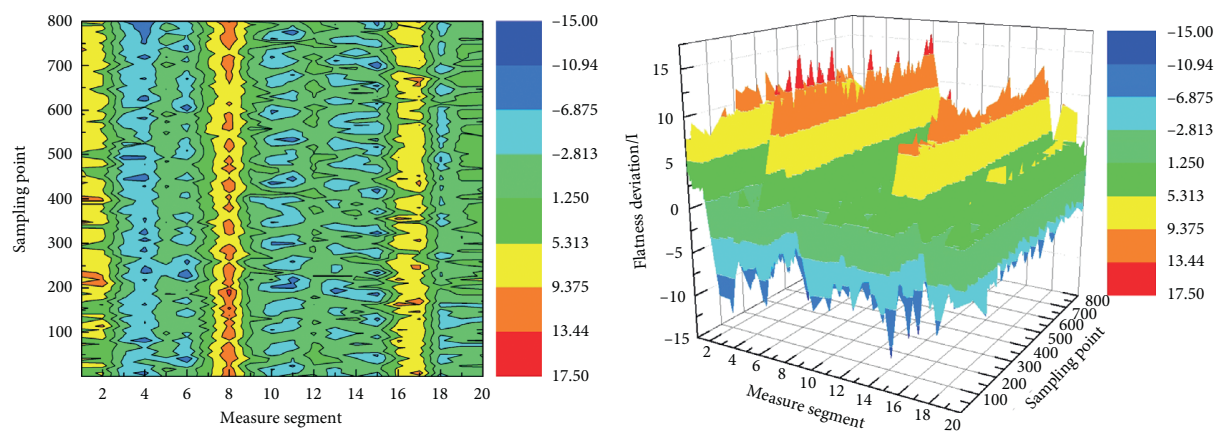

(a)
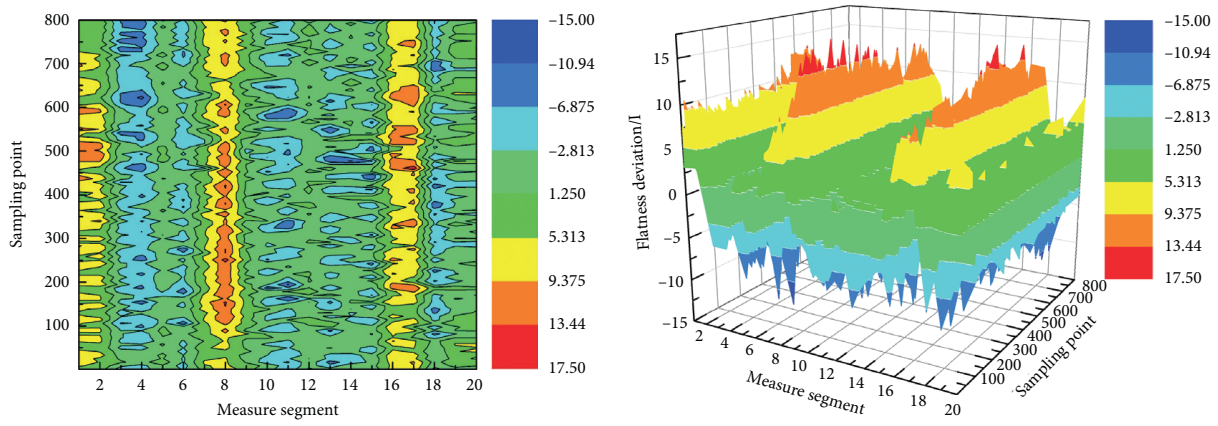

(b)
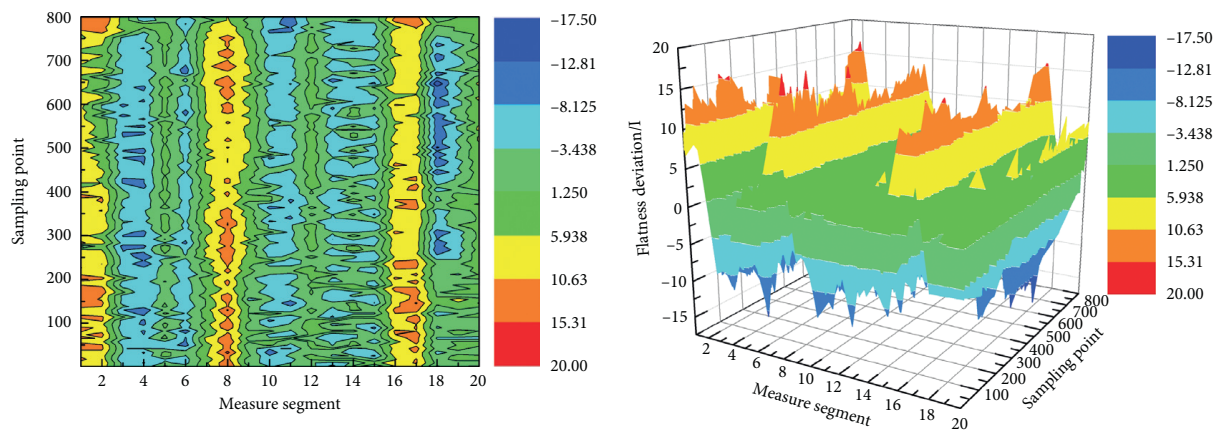

(c)

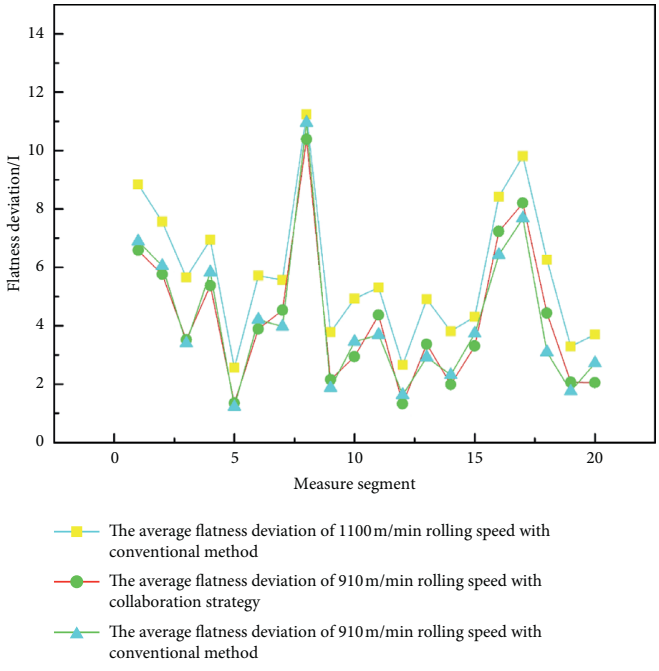

(d)

Figure 8: The flatness control effect of different rolling speed. (a) The control effect of $1100 \mathrm{~m} / \mathrm{min}$ rolling speed with using conventional model. (b) The control effect of $910 \mathrm{~m} / \mathrm{min}$ rolling speed with using collaboration strategy. (c) The control effect of $910 \mathrm{~m} / \mathrm{min}$ rolling speed with using conventional model. (d) The average flatness deviation of different rolling speed. 
TABLE 5: The experimental parameter of the flatness control effect test of different rolling force.

\begin{tabular}{lccrr}
\hline Test number & Gauge/mm & Strip & Rolling force/kN & Strategy \\
\hline 4 & $3.5 \times 1250 \longrightarrow 0.88 \times 1250$ & SPCC & $8300 \sim 8900$ & Collaboration strategy \\
5 & $3.5 \times 1250 \longrightarrow 0.88 \times 1250$ & SPCC & $7700-8300$ & Conventional method \\
6 & $3.5 \times 1250 \longrightarrow 0.88 \times 1250$ & SPCC & $8300 \sim 8900$ & Conventional method \\
\hline
\end{tabular}

TABLE 6: The average flatness deviation of different rolling force.

\begin{tabular}{|c|c|c|c|}
\hline $\begin{array}{l}\text { Measure } \\
\text { segment }\end{array}$ & $\begin{array}{l}\text { Difference between the average flatness } \\
\text { deviation of } 8300 \mathrm{kN} \sim 8900 \mathrm{kN} \text { rolling } \\
\text { force with conventional method and the } \\
\text { average flatness deviation of } \\
8300 \mathrm{kN} \sim 8900 \mathrm{kN} \text { rolling force with } \\
\text { collaboration strategy/I }\end{array}$ & $\begin{array}{l}\text { Difference between the average flatness } \\
\text { deviation of } 8300 \mathrm{kN} \sim 8900 \mathrm{kN} \text { rolling } \\
\text { force with conventional method and the } \\
\text { average flatness deviation of } \\
7700 \mathrm{kN} \sim 8300 \mathrm{kN} \text { rolling force with } \\
\text { conventional method/I }\end{array}$ & $\begin{array}{l}\text { Absolute value of difference between the } \\
\text { average flatness deviation of } \\
7700 \mathrm{kN}-8300 \mathrm{kN} \text { rolling force with } \\
\text { conventional method and the average } \\
\text { flatness deviation of } 8300 \mathrm{kN} \sim 8900 \mathrm{kN} \\
\text { rolling force with collaboration strategy/ } \\
\text { I }\end{array}$ \\
\hline 1 & 2.52 & 2.01 & 0.51 \\
\hline 2 & 1.33 & 1.58 & 0.24 \\
\hline 3 & 2.43 & 2.01 & 0.43 \\
\hline 4 & 2.00 & 1.81 & 0.18 \\
\hline 5 & 1.23 & 1.37 & 0.13 \\
\hline 6 & 1.02 & 2.17 & 1.15 \\
\hline 7 & 1.28 & 1.91 & 0.62 \\
\hline 8 & 1.59 & 1.05 & 0.53 \\
\hline 9 & 2.30 & 2.06 & 0.26 \\
\hline 10 & 0.88 & 0.82 & 0.05 \\
\hline 11 & 0.93 & 1.11 & 0.17 \\
\hline 12 & 0.65 & 0.67 & 0.02 \\
\hline 13 & 1.20 & 1.18 & 0.01 \\
\hline 14 & 0.99 & 0.85 & 0.13 \\
\hline 15 & 1.79 & 1.74 & 0.04 \\
\hline 16 & 1.23 & 0.83 & 0.39 \\
\hline 17 & 0.94 & 0.96 & 0.02 \\
\hline 18 & 2.15 & 2.71 & 0.55 \\
\hline 19 & 0.90 & 1.25 & 0.34 \\
\hline 20 & 1.61 & 1.57 & 0.04 \\
\hline
\end{tabular}
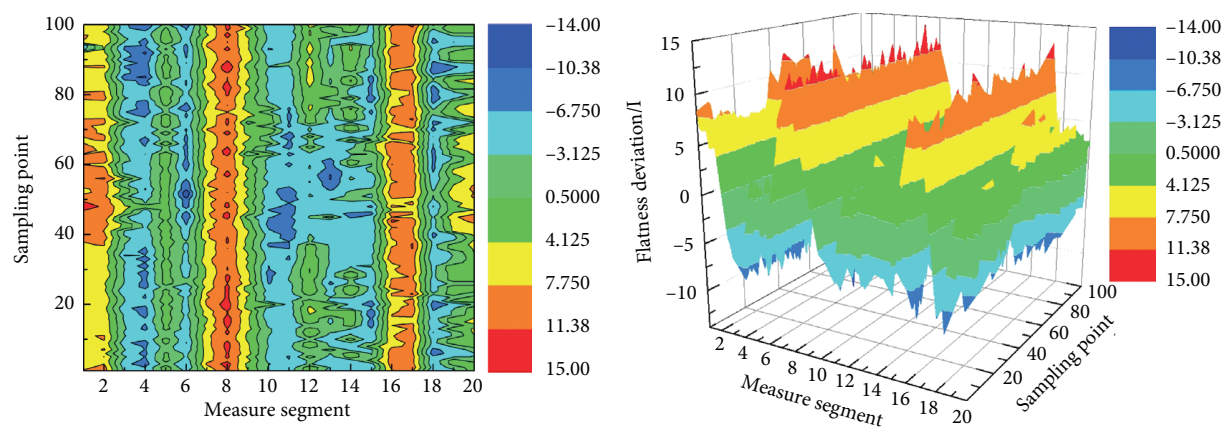

(a)

Figure 9: Continued. 

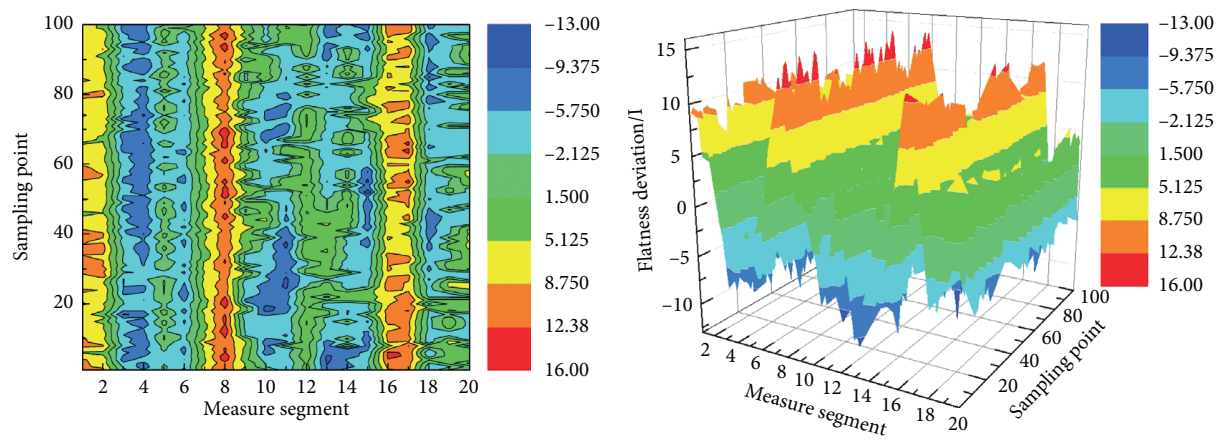

(b)
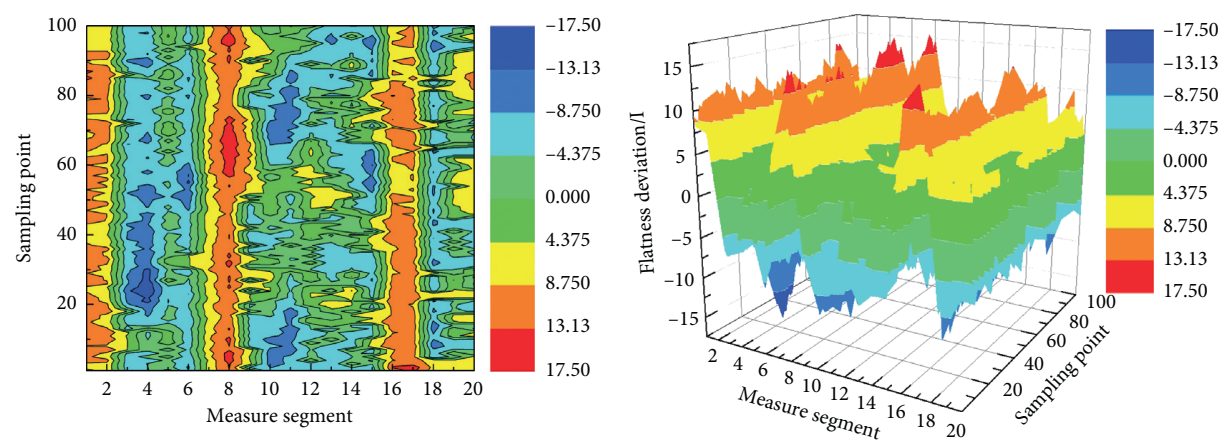

(c)

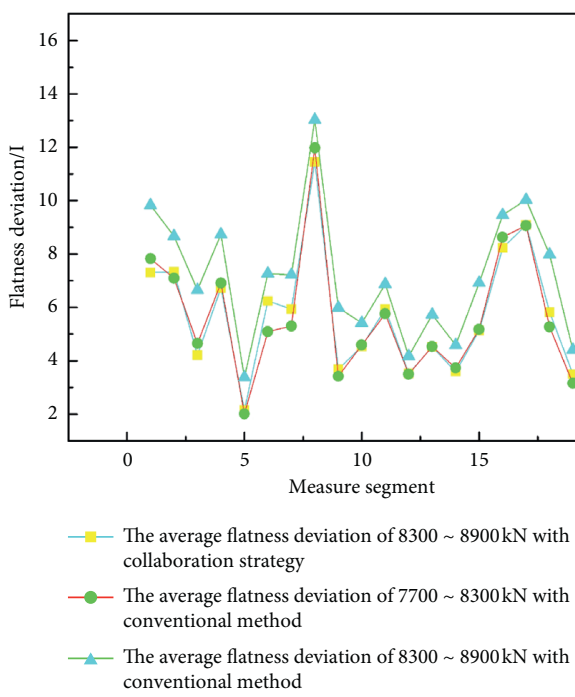

(d)

Figure 9: The flatness control effect of different rolling force. (a) The control effect of $8300 \mathrm{kN} \sim 8900 \mathrm{kN}$ rolling force with using collaboration strategy. (b) The control effect of $7700 \mathrm{kN}-8300 \mathrm{kN}$ rolling force with using conventional model. (c) The control effect of $8300 \mathrm{kN} \sim 8900 \mathrm{kN}$ rolling force with using conventional model. (d) The average flatness deviation of different rolling force.

TABLE 7: The experimental parameter of the flatness control effect test of different rolling reduction.

\begin{tabular}{lcccc}
\hline Test number & Gauge $/ \mathrm{mm}$ & Strip & Rolling reduction/\% & Strategy \\
\hline 7 & $2.5 \times 1250 \longrightarrow 0.58 \times 1250$ & Q195 & 15.89 & Conventional method \\
8 & $2.5 \times 1250 \longrightarrow 0.58 \times 1250$ & Q195 & 32.96 & Collaboration strategy \\
9 & $2.5 \times 1250 \longrightarrow 0.58 \times 1250$ & Q195 & 32.96 & Conventional method \\
\hline
\end{tabular}



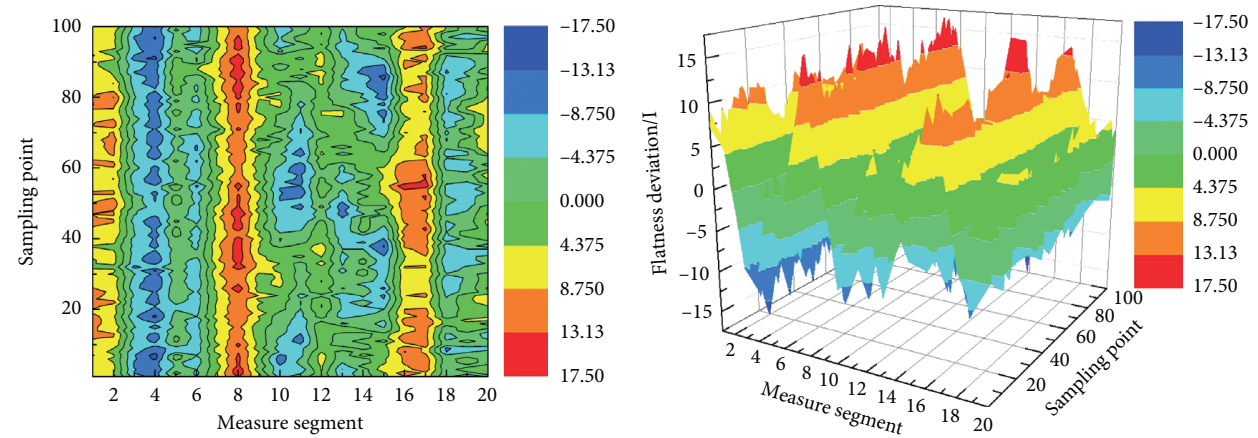

(a)
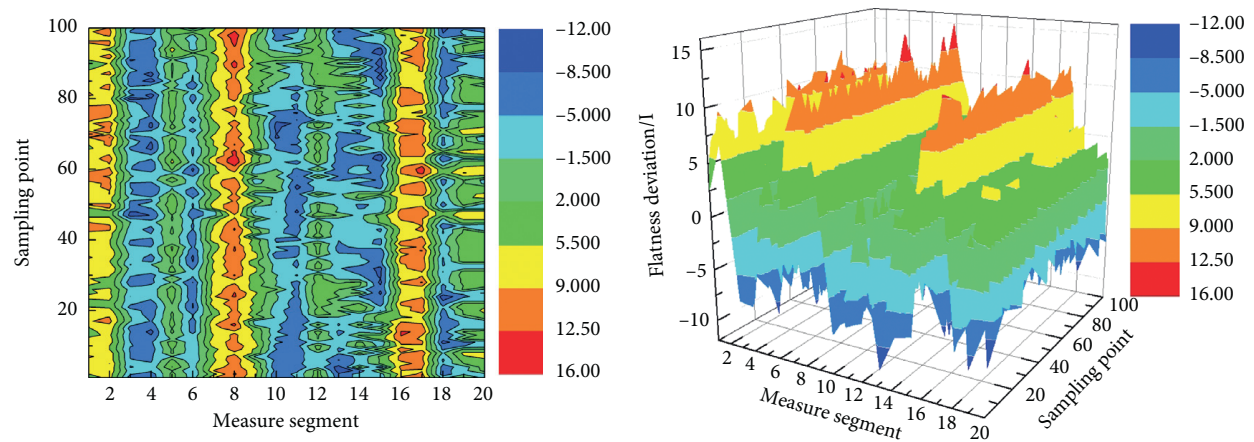

(b)
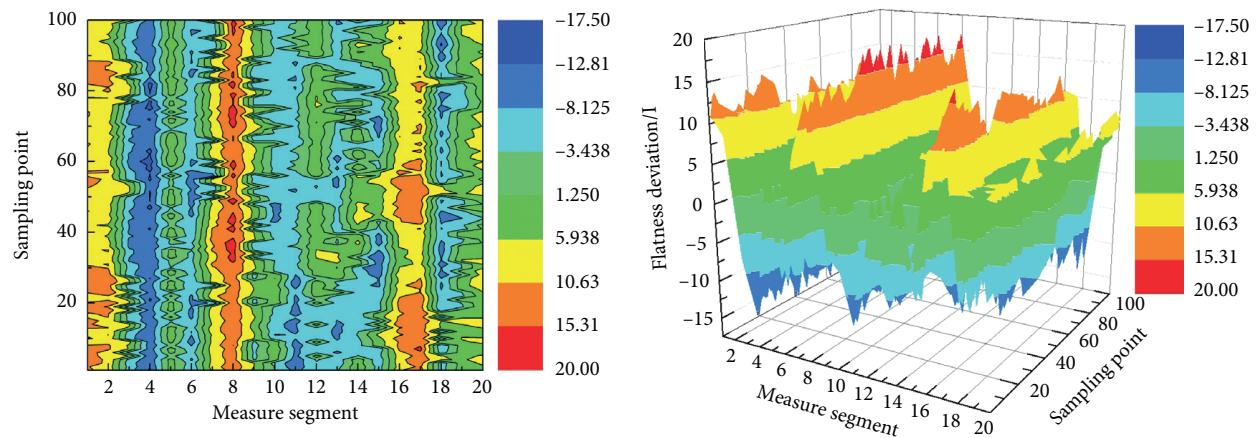

(c)

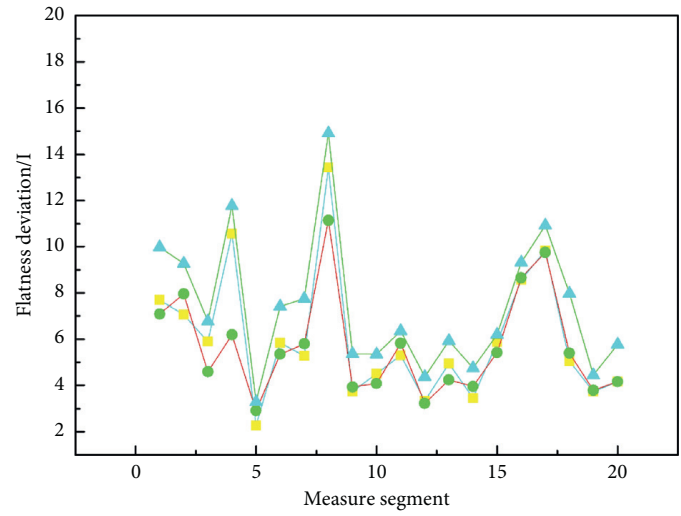

\footnotetext{
- The average flatness deviation of $15.89 \%$ roll reduction with conventional method

- The average flatness deviation of $32.96 \%$ roll reduction with collaboration strategy

4- The average flatness deviation of $32.96 \%$ roll reduction with conventional method
}

(d)

Figure 10: The flatness control effect of different rolling reduction. (a) The control effect of $15.89 \%$ rolling reduction with using conventional model. (b) The control effect of 32.96\% rolling reduction with using collaboration strategy model. (c) The control effect of $32.96 \%$ rolling reduction with using conventional model. (d) The average flatness deviation of different rolling reduction. 
TABLE 8: The average flatness deviation of different rolling reduction.

\begin{tabular}{|c|c|c|c|}
\hline $\begin{array}{l}\text { Measure } \\
\text { segment }\end{array}$ & $\begin{array}{c}\text { Difference between the average flatness } \\
\text { deviation of } 32.96 \% \text { rolling reduction } \\
\text { with conventional method and the } \\
\text { average flatness deviation of } 32.96 \% \\
\text { rolling reduction with collaboration } \\
\text { strategy/I }\end{array}$ & $\begin{array}{c}\text { Difference between the average flatness } \\
\text { deviation of } 32.96 \% \text { rolling reduction } \\
\text { with conventional method and the } \\
\text { average flatness deviation of } 15.89 \% \\
\text { rolling reduction with conventional } \\
\text { method/I }\end{array}$ & $\begin{array}{l}\text { Absolute value of difference between the } \\
\text { average flatness deviation of } 15.89 \% \\
\text { rolling reduction with conventional } \\
\text { method and the average flatness } \\
\text { deviation of } 32.96 \% \text { rolling reduction } \\
\text { with collaboration strategy/I }\end{array}$ \\
\hline 1 & 2.89 & 2.28 & 0.61 \\
\hline 2 & 1.32 & 2.22 & 0.90 \\
\hline 3 & 2.18 & 0.88 & 1.07 \\
\hline 4 & 5.89 & 1.21 & 1.31 \\
\hline 5 & 0.37 & 1.01 & 0.64 \\
\hline 6 & 2.06 & 1.57 & 0.49 \\
\hline 7 & 1.95 & 2.47 & 0.51 \\
\hline 8 & 3.76 & 1.49 & 1.26 \\
\hline 9 & 1.43 & 1.63 & 0.19 \\
\hline 10 & 1.25 & 0.83 & 0.42 \\
\hline 11 & 0.52 & 1.04 & 0.51 \\
\hline 12 & 1.15 & 1.04 & 0.11 \\
\hline 13 & 1.68 & 0.98 & 0.70 \\
\hline 14 & 0.79 & 1.30 & 0.50 \\
\hline 15 & 0.77 & 0.32 & 0.44 \\
\hline 16 & 0.65 & 0.74 & 0.08 \\
\hline 17 & 1.16 & 1.08 & 0.07 \\
\hline 18 & 2.58 & 2.93 & 0.34 \\
\hline 19 & 0.66 & 0.71 & 0.04 \\
\hline 20 & 1.61 & 1.60 & 0.01 \\
\hline
\end{tabular}

changed from $15.89 \%$ to $32.96 \%$ and the control method is changed from conventional model to collaboration strategy model, the change of average flatness deviation is small. The maximum changing magnitude is $1.31 \mathrm{I}$. It indicates that the rolling reduction can be compensated by using collaboration strategy model. The maximal compensation efficiency of rolling reduction is $36.77 \%$.

\section{Conclusion}

(1) The flatness actuator group collaboration strategy is created on account of the actual flatness condition discrimination factor. In the newly raised collaboration strategy model, the actual flatness situation can be calculated and identified. What is more, the overall regulation capacity of flatness adjustment actuator after the combination is made to match with the flatness defect so that the flatness control system can give full play to its potential.

(2) In online test experiment using collaboration strategy model, a preliminary finding is achieved: When the strip rolling speed is increased from $910 \mathrm{~m} / \mathrm{min}$ to $1100 \mathrm{~m} / \mathrm{min}$, the maximal compensation efficiency of rolling speed is $51.89 \%$. When the rolling force is increased from $7700 \mathrm{kN}-8300 \mathrm{kN}$ to $8300 \mathrm{kN} \sim 8900 \mathrm{kN}$, the maximal compensation efficiency of rolling force is $42.88 \%$. When the rolling reduction is increased from $15.89 \%$ to $32.96 \%$, the maximal compensation efficiency of rolling reduction is $36.77 \%$. Thus, it can be seen that the flatness control effect is improved under rolling conditions of low rolling speed, large rolling force, and high rolling reduction by using collaboration strategy.

\section{Data Availability}

The data used to support the findings of this study are available from the corresponding author upon request.

\section{Conflicts of Interest}

The authors declare that they have no conflicts of interest.

\section{Acknowledgments}

This study was financially supported by the National Key R\&D Program of China (2017YFB0304100), the National Natural Science Foundation of China (nos. 51804133, 51905068, and 61703200), the Natural Science Foundation of Jiangsu Provincial of China (nos. BK20180977 and BK20181024), and the Foundation of Nanjing Institute of Technology (no. YKJ201867).

\section{References}

[1] S. Abdelkhalek, P. Montmitonnet, N. Legrand, and P. Buessler, "Coupled approach for flatness prediction in cold rolling of thin strip," International Journal of Mechanical Sciences, vol. 53, no. 9, pp. 661-675, 2011.

[2] X. Zhang, T. Xu, L. Zhao, H. Fan, and J. Zang, "Research on flatness intelligent control via GA-PIDNN," Journal of Intelligent Manufacturing, vol. 26, no. 2, pp. 359-367, 2013.

[3] P. Wang, D. Qiao, D. Zhang, J. Sun, and H. Liu, "Optimal multi-variable flatness control for a cold rolling mill based on 
a box-constraint optimisation algorithm," Ironmaking \& Steelmaking, vol. 43, no. 6, pp. 426-433, 2016.

[4] K. Prinz, A. Steinboeck, and A. Kugi, "Optimization-based feedforward control of the strip thickness profile in hot strip rolling," Journal of Process Control, vol. 64, pp. 100-111, 2018.

[5] Q.-L. Wang, J. Sun, X. Li, Y.-M. Liu, P.-F. Wang, and D.-H. Zhang, "Numerical and experimental analysis of strip cross-directional control and flatness prediction for UCM cold rolling mill," Journal of Manufacturing Processes, vol. 34, pp. 637-649, 2018.

[6] S. Voronin, D. Y. Usatyi, V. R. Gasiyarov et al., "Analysis of the use of cambered roll with the roll shift system CVC to adjust the gap on the hot plate mill," Russian Internet Journal of Industrial Engineering, vol. 3, no. 1, pp. 45-48, 2015.

[7] X. Ju and R. Mahnken, "Goal-oriented adaptivity for linear elastic micromorphic continua based on primal and adjoint consistency analysis," International Journal for Numerical Methods in Engineering, vol. 112, no. 8, pp. 1017-1039, 2017.

[8] H. N. Bu, Z. W. Yan, D. H. Zhang, and S. Z. Chen, "Rolling schedule multi-objective optimizationbased on influence function for thin gauge steel strip in tandem cold rolling," Scientia Iranica, vol. 23, no. 6, pp. 2663-2672, 2016.

[9] C.-Y. Jia, T. Bai, X.-Y. Shan, F.-J. Cui, and S.-J. Xu, "Cloud neural fuzzy PID hybrid integrated algorithm of flatness control," Journal of Iron and Steel Research International, vol. 21, no. 6, pp. 559-564, 2014.

[10] C. Liu, B. Liu, L. Zhao, Y. Xing, C. Ma, and H. Li, "A differential quadrature hierarchical finite element method and its applications to vibration and bending of Mindlin plates with curvilinear domains," International Journal for Numerical Methods in Engineering, vol. 109, no. 2, pp. 174-197, 2016.

[11] H. Liu, H. T. He, X. Y. Shan et al., "Flatness control based on dynamic effective matrix for cold strip mills," Chinese Journal of Mechanical Engineering, vol. 22, no. 2, pp. 287-296, 2009.

[12] H.-M. Liu, X.-Y. Shan, and C.-Y. Jia, "Theory-intelligent dynamic matrix model of flatness control for cold rolled strips," Journal of Iron and Steel Research International, vol. 20, no. 8, pp. 1-7, 2013.

[13] D. C. Tran, N. Tardif, and A. Limam, "Experimental and numerical modeling of flatness defects in strip cold rolling," International Journal of Solids and Structures, vol. 69-70, pp. 343-349, 2015.

[14] N. Mathieu, M. Potier-Ferry, and H. Zahrouni, "Reduction of flatness defects in thin metal sheets by a pure tension leveler," International Journal of Mechanical Sciences, vol. 122, pp. 267-276, 2017.

[15] R. Nakhoul, P. Montmitonnet, and N. Legrand, "Manifested flatness defect prediction in cold rolling of thin strips," International Journal of Material Forming, vol. 8, no. 2, pp. 283-292, 2015.

[16] M. Salimi and M. M. Sahebifard, "Optimization of strip profile and flatness using hybrid neural-GA algorithm," Steel Research International, vol. 81, no. 9, pp. 154-157, 2010.

[17] W. Q. Sun, B. Li, J. Shao et al., "Research on crown \& flatness allocation strategy of hot rolling mills," International Journal of Simulation Modelling, vol. 15, no. 2, pp. 327-340, 2016.

[18] D. C. Tran, N. Tardif, H. El Khaloui, and A. Limam, "Thermal buckling of thin sheet related to cold rolling: latent flatness defects modeling," Thin-Walled Structures, vol. 113, pp. 129-135, 2017.

[19] X. Zhang, L. Zhao, J. Zang, H. Fan, and L. Cheng, "Flatness intelligent control based on T-S cloud inference neural network," Isij International, vol. 54, no. 11, pp. 2608-2617, 2014.
[20] N. Lu, B. Jiang, and J. Lu, "Data mining-based flatness pattern prediction for cold rolling process with varying operating condition," Knowledge and Information Systems, vol. 41, no. 2, pp. 355-378, 2014.

[21] P.-f. Wang, Y. Peng, H.-m. Liu, D.-h. Zhang, and J.-s. Wang, "Actuator efficiency adaptive flatness control model and its application in $1250 \mathrm{~mm}$ reversible cold strip mill," Journal of Iron and Steel Research International, vol. 20, no. 6, pp. 13-20, 2013.

[22] L. P. Yang, H. X. Yu, D. C. Wang et al., "Intelligent shape regulation cooperative model of cold rolling strip and its application," Steel Research International, vol. 88, no. 7, pp. 1-11, 2017.

[23] T. Sumeet, T. C. Kevin, and J. D. Louis, "Error modeling for surrogates of dynamical systems using machine learning," International Journal for Numerical Methods in Engineering, vol. 112, no. 12, pp. 1801-1827, 2017.

[24] X.-L. Zhang, L. Cheng, S. Hao, W.-Y. Gao, and Y.-J. Lai, "The new method of flatness pattern recognition based on GARBF-ARX and comparative research," Nonlinear Dynamics, vol. 83, no. 3, pp. 1535-1548, 2016.

[25] X.-L. Zhang, L. Cheng, S. Hao, W.-Y. Gao, and Y.-J. Lai, "Optimization design of RBF-ARX model and application research on flatness control system," Optimal Control Applications and Methods, vol. 38, no. 1, pp. 19-35, 2017. 